\title{
Limitação de esforço terapêutico na pessoa com lesão encefálica grave
}

Henrique de Alencar Gomes ${ }^{1}$, Mônica Adelaide Almeida ${ }^{2}$, Terezinha Valéria Ferreira Matoso ${ }^{3}$, Maria Angélica Assunção Viana ${ }^{4}$, Maria Bernadete Cardoso Rezende ${ }^{5}$, Maíza Ângela Ferreira Bento ${ }^{6}$, Tatiane Santos Fonseca Guimarães ${ }^{7}$, Sabrina Vilane de Oliveira Alcântara $^{8}$, Ary Demétrio Júnior ${ }^{9}$, Ana Paula Gomes Costa Silva ${ }^{10}$, Cibele Renata de Paula Moreira ${ }^{11}$, Daniela Simplício Vieira Albergaria ${ }^{12}$, Marília Káthya Coutinho ${ }^{13}$, Marli Medeiros ${ }^{14}$, Roseli Melo Silva de Souza ${ }^{15}$, Polianna Cristina Pires Dumont ${ }^{16}$

\section{Resumo}

As discussões a respeito das condutas de limitação de esforço terapêutico (LET) são frequentes nas unidades de terapia intensiva e na especialidade médica oncológica e são também importantes em contextos hospitalares de internação de longa permanência para vítimas de grandes traumas e agravos que necessitam de cuidados prolongados à saúde e de reinserção social. Na prática clínica, a tomada de decisão para LET é complexa e deve envolver o indivíduo, a família e a equipe multiprofissional. O objetivo deste artigo é discorrer a respeito da LET como um abrangente processo de "adequação de medidas" por agregação consensual de fatores centrado na pessoa, pautado por intensificação dos cuidados paliativos.

Palavras-chave: Direito a morrer. Bioética. Cuidados paliativos. Tomada de decisões. Traumatismo encefálico crônico. Estado vegetativo persistente.

\section{Resumen}

\section{La limitación del esfuerzo terapéutico en persona con lesión cerebral grave}

Las discusiones acerca de las conductas de limitación del esfuerzo terapéutico (LET) son comunes en las unidades de cuidados intensivos y oncología y también son importantes en hospitales de larga estancia para las personas víctimas de traumatismos graves y lesiones que requieren atención de salud a largo plazo y la reintegración social. En la práctica clínica, la toma de decisiones para la LET es compleja y debe abordar al individuo, la familia y el equipo multiprofesional. El propósito de este artículo es discutir sobre LET como un proceso integral de "adecuación de medidas" mediante la agregación consensual de factores centrados en la persona, marcado por la intensificación de los cuidados paliativos.

Palabras-clave: Derecho a morir. Bioética. Cuidados paliativos. Toma de decisiones. Traumatismo encefálico crónico. Estado vegetativo persistente.

\section{Abstract \\ Limitation of therapeutic effort in person with severe brain injury}

Discussions about the limitation of therapeutic effort are common in intensive care units and oncology and are also important in long stay hospitals for victims of major trauma and injuries that require long-term health care and social reintegration. In clinical practice, the decision making for limitation of therapeutic effort is complex and multifactorial and should involve the individual, the family and the multidisciplinary team. The purpose of this article is to discuss about limitation of therapeutic effort as a comprehensive process of "adjustment of measures" for consensual aggregation of person-centered factors, marked by intensification of palliative care.

Key words: Right to die. Bioethics. Palliative care. Decision making. Brain injury, chronic. Persistent vegetative state.

1. Doutorando henrique.gomes@fhemig.mg.gov.br 2. Especialista hcm.cuidar@fhemig.mg.gov.br 3. Especialista tvfm@terra.com. br 4. Especialista mariaangelica.1@oi.com.br 5. Especialista deterezende@gmail.com 6. Graduada maizaangela@gmail.com 7. Graduada tatiane.fono@yahoo.com.br 8. Graduada brinafono@yahoo.com.br 9. Especialista arydemetrio@gmail.com 10. Graduada anapaulagcs@yahoo.com.br 11. Graduada hcm.cuidar@fhemig.mg.gov.br 12. Graduada daniela.albergaria@fhemig.mg.gov.br 13. Especialista kathya.coutinho@fhemig.mg.gov.br 14. Graduada marlimednut@hotmail.com 15. Técnica hcm.cuidar@fhemig.mg.gov.br 16. Graduada poliannacristina@yahoo.com.br - Fundação Hospitalar do Estado de Minas Gerais, Sabará/MG, Brasil.

\section{Correspondência}

Henrique de Alencar Gomes - Rua Francisco Lobo, 558/301, Esplanada CEP 30280-080. Belo Horizonte/MG, Brasil.

Declaram não haver conflito de interesse. 
O progressivo desenvolvimento tecnológico e a adoção de medidas efetivas de suporte à vida têm possibilitado aumento no número de sobreviventes de grandes traumas nas unidades de terapia intensiva (UTI) ${ }^{1,2}$. Consequentemente, observa-se crescente demanda de pacientes de internação de longa permanência por sequelas neurológicas graves e totalmente dependentes em suas atividades de vida diária. É o caso dos pacientes comatosos, não responsivos pós-coma ou minimamente responsivos.

A tônica da dignidade humana no morrer e os dilemas éticos e legais no que concerne às políticas de alocação de recursos, ao adequado tratamento a ser prestado ao paciente em processo de declínio clínico e funcional e à complexidade para identificar limites terapêuticos nítidos, principalmente nas vítimas de lesão encefálica grave, suscitam debates contínuos sobre a limitação de esforço terapêutico (LET). As discussões a respeito das condutas de LET são frequentes nas UTI e na especialidade médica oncológica. Reflexões sobre o processo de tomada de decisão em LET também são necessárias em contextos hospitalares de internação de longa permanência para casos neurológicos. Exemplificando, a equipe multiprofissional pode se deparar com um cenário com paciente em declínio clínico, com perda de autonomia por lesão neurológica grave há meses ou anos e uma família psicológica e socialmente desestruturada, quando presente, ou mesmo com a não identificação de familiares.

A expressão "limitação de esforço terapêutico" tem sido questionada por alguns autores ${ }^{3}$. Herreros e colaboradores, por exemplo, afirmam que a "limitação" não se restringe à terapêutica, abrangendo também procedimentos diagnósticos. Além dessa consideração, a expressão pode trazer a conotação negativa de "limitação de esforço" de um profissional ou equipe, com a ideia de relativização do "esforço". Por fim, estar "fora de possibilidade terapêutica" pode remeter ao "nada que fazer" em uma circunstância que, paradoxalmente, se intensificam os cuidados paliativos a ponto de se tornarem exclusivos. Assim, Herreros e colaboradores (2012) têm proposto a expressão adequação de medidas (AM) nas discussões pertinentes à LET ${ }^{3}$.

A adoção da expressão AM neste artigo reflete a proposta de reafirmação de valores éticos e humanos na assistência à pessoa com lesão encefálica grave, em terminalidade ou não. Portanto, o objetivo principal é discorrer a respeito da tomada de decisão da AM como processo de agregação consensual de fatores centrado na pessoa, buscando estimular e ampliar reflexões sob as perspectivas ética, normativa e clínica.

\section{Adequação de medidas}

A AM estabelece-se em pacientes cuja condição clínica é grave, irreversível ou terminal e pode ser definida como condutas médicas restritivas, nas quais se limita o uso de certos recursos terapêuticos 2. A ortotanásia ou a "arte de morrer bem" aproxima-se dessa definição, humana do ponto de vista do manejo dos cuidados ao sofrimento do paciente e seus familiares no processo de morrer, distinguindo-se da distanásia e eutanásia, nas quais há a intenção de meramente prolongar o morrer ou de acelerar tal processo natural, respectivamente ${ }^{2,4}$. Apesar da distinção teórica dessas definições, os limites conceituais na prática clínica ante pacientes de longa permanência hospitalar com lesão encefálica grave podem por vezes não ser tão nítidos, levando em consideração a pessoa internada, a família e a equipe multiprofissional. Assim, a tomada de decisão clínica quanto a não aplicação ou suspensão de medidas terapêuticas nesse perfil clínico exige reflexões constantes sobre a relação entre prognóstico de vida e de qualidade de vida futura durante todo o período de internação.

Uma perspectiva humanizada advinda da filosofia paliativista e que vem sendo transformada em realidade refere-se ao entendimento de que o modelo curativo não precede linearmente ao paliativo, mas que ambos atuam concomitantemente, de maneira sobreposta, na busca da garantia do alívio de sintomas que causem desconforto desde o diagnóstico da doença que ameace a vida ${ }^{5,6}$. Particularmente no âmbito hospitalar, preconiza-se essa atuação concomitante desde a admissão na UTI, passando pela internação hospitalar e estendendo-se ao pósóbito com suporte psicológico aos familiares ${ }^{5,6}$. Desse modo, a AM poderia ser também entendida como o processo da sobreposição do modelo curativo pelo paliativo, firmando o cuidado paliativo individualizado e humanizado como a terapêutica a ser intensificada ou exclusiva. Recomendações para AM, como a proposta pela Sociedad Española de Medicina Intensiva, podem ser atualmente entendidas como indicadores de qualidade de assistência ${ }^{7}$. 
AM como "processo de tomada de decisão por agregação consensual de fatores centrado na pessoa"

\section{Elementos fundamentais do processo de tomada} de decisão de AM

O governo australiano, por meio do National Health and Medical Research Council, preconiza o uso da palavra "pessoa" ao invés de "paciente" a fim de ressaltar a autonomia, os valores e crenças pessoais, familiares e espirituais e o contexto socioeconômico do indivíduo ${ }^{8}$. Preconiza ainda ao se referir a uma pessoa o uso das expressões "não responsiva póscoma" ou "minimamente responsiva", e não "estado vegetativo", por propósito ético com vistas a evitar tal expressão potencialmente pejorativa ${ }^{8}$. Em conformidade, este artigo propõe o uso da palavra "pessoa" e expressões "não responsiva pós-coma" ou "minimamente responsiva" nas reflexões sobre AM.

A tomada de decisão é permeada por subjetividade dos envolvidos. Herreros e colaboradores destacam a complexidade temática da AM ao relatarem que critérios racionais podem servir de argumentos para a tomada de decisão, porém não eliminam por completo a incerteza do processo ${ }^{3}$. Moritz e colaboradores destacam que devem ser considerados critérios objetivos e subjetivos neste amplo processo de tomada de decisão que certamente é individual $^{2}$.
Fluxogramas para a AM têm sido propostos na literatura (Figuras 1 e 2) ) $^{6,9}$. A análise dessas representações gráficas da AM permite destacar alguns pontos importantes. A pessoa, a família (representante legal) e a equipe multidisciplinar são elementos fundamentais intrínsecos que precisam ser tomados como partes participativas do processo decisório. A autonomia da pessoa (as preferências) na tomada de decisão, ou da família (representante legal) quando se aplica, é a principal norteadora do processo, tanto da perspectiva ética quanto legal.

A decisão é consensual, multifacetada e compartilhada a partir de questionamentos a serem discutidos em níveis e momentos pertinentes a cada um dos elementos intrínsecos da AM: a precisão do diagnóstico, as possibilidades de sucesso das terapias disponíveis, o esgotamento dos meios terapêuticos, a probabilidade de cura e de esperança de vida para o atual estágio evolutivo em que se encontra "esta" pessoa, ou seja, o prognóstico de vida - um dos maiores desafios da Medicina, levando-se em consideração a qualidade de vida (prévia e futura), a idade e a deterioração cognitiva, caso a caso ${ }^{3,6,9}$. Para isso, deve ser respeitado o tempo da pessoa e de seus familiares no que concerne à compreensão do processo, durante o qual se deve garantir os cuidados paliativos e o apoio a cada um dos três elementos participativos. Além disso, toda e qualquer decisão pode ser reavaliada a qualquer momento ${ }^{6}$.

Figura 1. Fluxograma para a tomada de decisão de AM proposto por Moritz e colaboradores (2011)
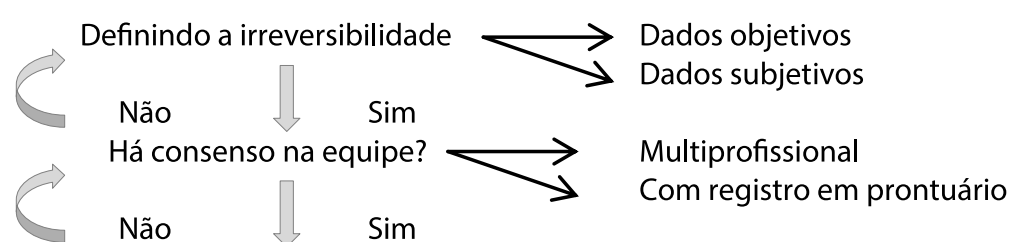

Abrir discussão com a família ou representante

Não Sim

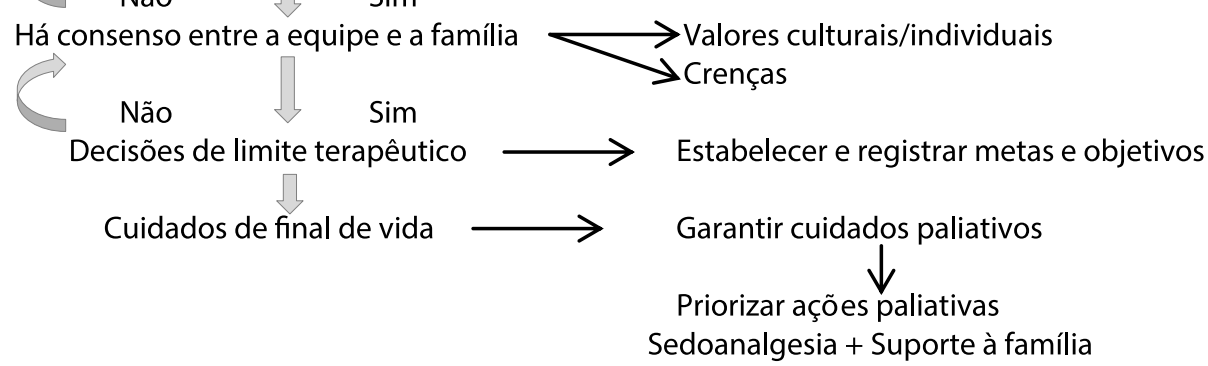

Salienta-se $\rightarrow$ Apoio ao paciente, seus familiares e à equipe multiprofissional deve ser garantido durante todo o processo. $\rightarrow$ Toda e qualquer decisão pode ser reavaliada a qualquer momento.

$\rightarrow$ Deve ser respeitado o tempo do paciente e dos familiares no que concerne à compreensão do processo. 
Figura 2. Fluxograma para a tomada de decisão de AM proposto por Ortega e Cabré (2008)

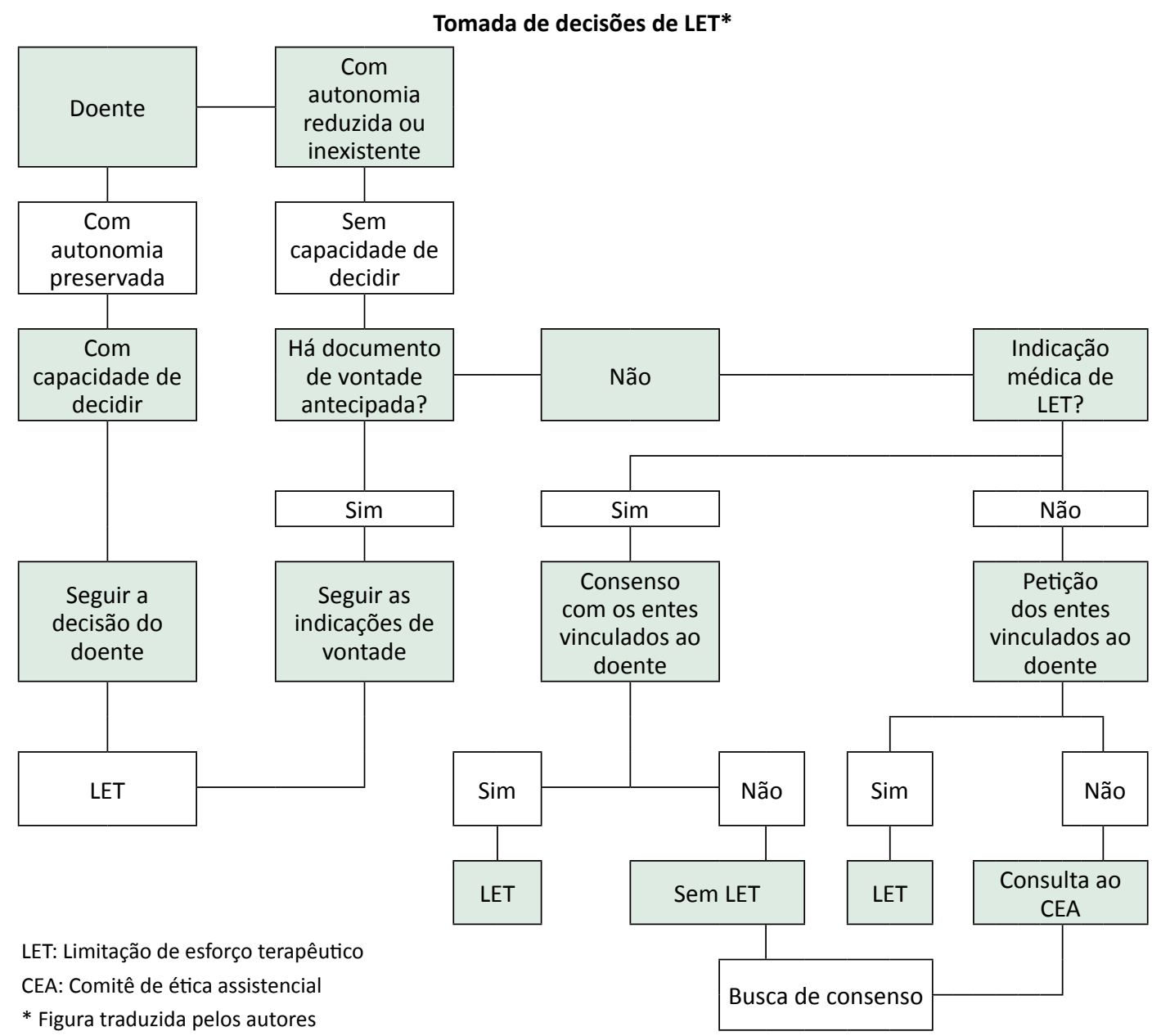

Princípios éticos fundamentais para o processo de tomada de decisão de AM

A bioética orienta-se basicamente por quatro princípios: a autonomia, a beneficência, a não maleficência e a justiça ${ }^{2}$. Estes princípios podem ser entendidos como orientadores para justificar os preceitos médicos e as ações humanas na área das ciências da vida e dos cuidados de saúde ${ }^{10}$.

O princípio da autonomia refere-se à autodeterminação, ao autogoverno, ao poder de decidir sobre si mesmo. Esta capacidade de fazer as próprias escolhas implica responsabilidades e representa um direito irrenunciável. De maneira geral, o respeito à autonomia faz com que a autoridade decisória resida na pessoa e, sendo esta incapaz, em seu representante legal, geralmente um familiar mais próximo ${ }^{2,10}$.

O princípio da beneficência constitui-se no dever de promover benefícios a outrem, independentemente deste desejá-los. Supõe também a obrigação ética principal de proporcionar tais benefícios suprimindo-se os malefícios. O médico deve comprometer-se pela busca do cumprimento dos objetivos da Medicina, que podem ser resumidos em tratar a pessoa com o melhor possível, restaurando-lhe a saúde, preservando a vida e aliviando o sofrimento ${ }^{2,10}$.

O princípio da não maleficência obriga a não prejudicar o outro e é violado quando se aplica a uma pessoa um tratamento que não está indicado, que causa complicação, dano ou qualquer tipo de lesão. O profissional se compromete a avaliar e evitar os danos previsíveis ${ }^{2,10}$. De maneira geral, os princípios da beneficência e da não maleficência devem ser analisados conjuntamente a fim de que as decisões tenham a utilidade sobreposta ao prejuízo. A frase de Hipócrates reflete isso: Pratique duas coisas ao lidar com as doenças; auxilie ou não prejudique o paciente ${ }^{2}$.

O princípio da justiça como dever prima facie envolve questões ético-culturais e temporais e 
baseia-se na possibilidade de que a distribuição dos bens sociais não se realize segundo os méritos das pessoas implicadas ${ }^{2,10}$. O princípio da justiça rege que a distribuição dos recursos sanitários, deveres e benefícios sociais seja coerente e adequada. Isso está em concordância com a justiça formal proposta por Aristóteles, afirmando a disposição imparcial para reconhecimento do direito de cada um e a disponibilização de tratamento equânime ${ }^{2,10}$.

Apesar da clareza conceitual de cada um dos quatro princípios bioéticos da prática médica, continuam incessantes os questionamentos da aplicação prática clínica coletiva dos mesmos na AM. Moritz e colaboradores afirmam que certamente as decisões terapêuticas são individuais, baseadas em amplo contexto que envolve a avaliação de aspectos clínicos e sociais baseada em critérios objetivos e subjetivos. Entretanto, sem sombra de dúvida, existe embasamento ético na promoção da ortotanásia e na implantação dos cuidados paliativos aos pacientes críticos $^{2}$. Para estes autores, a referida ortotanásia aproxima-se de sua referência conceitual à LET, condutas médicas restritivas em que se limita o uso de certos recursos inadequados ou inúteis, em oposição à prática de qualquer terapia que somente prolongará o morrer e aumentará o sofrimento da pessoa e de seus familiares ${ }^{2}$.

Aspectos normativos pertinentes ao processo de tomada de decisão de AM

Pertinente à temática da $\mathrm{AM}$, Torres afirma que o prolongamento do morrer, ou seja, a obstinação terapêutica, propiciada principalmente pela tecnologia do mundo moderno, é estimulada pela prática de uma "medicina defensiva", consistente na adoção de todos os recursos e procedimentos disponiveis, ainda que sabidamente inúteis e desnecessários, com o único objetivo de fazer prova de uma boa atuação profissional. No tratamento de pacientes com doenças terminais, o temor em face da possibilidade de responsabilização ética, civil e criminal pela morte tem conduzido os médicos à promoção da distanásia ${ }^{11}$.

Do ponto de vista normativo, em novembro de 2006 o Conselho Federal de Medicina (CFM) publicou a Resolução CFM 1.805/06, descrevendo em seu artigo $1^{\circ}$ que: É permitido ao médico limitar ou suspender procedimentos e tratamento que prolonguem a vida do doente, em fase terminal de enfermidade grave e incurável, respeitada a vontade da pessoa ou de seu representante legal. No parágrafo $4^{\circ}$ deste artigo, descreve: Em se tratando de doente incapaz, ausente o representante legal, incumbirá ao médico decidir sobre as medidas mencionadas no caput deste artigo. Além disso, descreve em seu artigo $2^{\circ}$ que: $O$ doente continuará a receber todos os cuidados necessários para aliviar os sintomas que levam ao sofrimento, assegurada a assistência integral, o conforto físico, psíquico, social, espiritual, inclusive assegurando a ele o direito da alta hospitalar ${ }^{12}$.

Destaca-se, nestes artigos e parágrafo da resolução, o balizamento pelo princípio da autonomia no processo decisório de limitação terapêutica: primeiro a pessoa, segundo o representante legal, e finalmente o médico. Além disso, garantem-se os cuidados paliativos contínuos. Em 2007, esta resolução foi suspensa e, em dezembro de 2010, revogou-se a liminar que a suspendia após debates do Ministério Público Federal, representantes do CFM, profissionais da saúde e representantes da sociedade acerca da ortotanásia como conduta médica moralmente legítima e legalmente lícita ${ }^{11}$.

Em concordância com esta resolução, o Código de Ética Médica (CEM) de 2010, no item XXII do Capítulo I, Princípios Fundamentais, dispõe que nas situações clínicas irreversíveis e terminais, o médico evitará a realização de procedimentos diagnósticos e terapêuticos desnecessários e propiciará aos pacientes sob sua atenção todos os cuidados paliativos apropriados ${ }^{13}$.

Além disso, o artigo 41 do CEM afirma ser vedado ao médico abreviar a vida do paciente, ainda que a pedido deste ou de seu representante legal. Este artigo contempla em seu parágrafo único que nos casos de doença incurável e terminal, deve o médico oferecer todos os cuidados paliativos disponíveis sem empreender ações diagnósticas ou terapêuticas inúteis ou obstinadas, levando sempre em consideração a vontade expressa do paciente ou, na sua impossibilidade, a de seu representante legal ${ }^{13}$. Ressalta-se novamente a autonomia da pessoa ou do representante legal, garantindo-se as ações paliativas na terminalidade.

Quanto a essa autonomia da pessoa, a Resolução CFM 1.995/12 ${ }^{14}$ dispõe sobre as diretivas antecipadas de vontade dos pacientes, definindo-a em seu artigo $1^{\circ}$ como o conjunto de desejos, prévia e expressamente manifestados pelo paciente, sobre cuidados e tratamentos que quer, ou não, receber no momento em que estiver incapacitado de expressar, livre e autonomamente, sua vontade. No artigo $2^{\circ}$ a norma refere-se às decisões sobre cuidados e tratamentos de pacientes que se encontram incapazes de comunicar-se ou de expressar de maneira livre e independente suas vontades, indicando que o médico deverá levar em consideração suas diretivas 
antecipadas de vontade, ressaltando nos parágrafos seguintes que:

$\S 1^{\circ}$ Caso o paciente tenha designado um representante para tal fim, suas informações serão levadas em consideração pelo médico. § $2^{\circ} \mathrm{O}$ médico deixará de levar em consideração as diretivas antecipadas de vontade do paciente ou representante que, em sua análise, estiverem em desacordo com os preceitos ditados pelo Código de Ética Médica. $\S 3^{\circ}$ As diretivas antecipadas do paciente prevalecerão sobre qualquer outro parecer não médico, inclusive sobre os desejos dos familiares. $\S 4^{\circ} \mathrm{O}$ médico registrará, no prontuário, as diretivas antecipadas de vontade que Ihes foram diretamente comunicadas pelo paciente. $\S 5^{\circ}$ Não sendo conhecidas as diretivas antecipadas de vontade do paciente, nem havendo representante designado, familiares disponíveis ou falta de consenso entre estes, o médico recorrerá ao Comitê de Bioética da instituição, caso exista, ou, na falta deste, à Comissão de Ética Médica do hospital ou ao Conselho Regional e Federal de Medicina para fundamentar sua decisão sobre conflitos éticos, quando entender esta medida necessária e conveniente ${ }^{14}$.

Esta resolução reforça a autonomia da pessoa acerca dos seus cuidados e tratamentos desde que em consonância com o CEM. Respalda também a tomada de decisão médica em situações de AM em pessoas comatosas, não responsivas pós-coma ou incapazes mentalmente, sem referência familiar ou de representante legal, desamparadas socialmente - uma realidade hospitalar que não deveria ser negligenciada. A partir da reflexão das normativas da prática médica no contexto da terminalidade e dos cuidados paliativos, podem ser constatados os princípios e os aspectos éticos e normativos intrínsecos à AM. Nesse sentido, Moritz e colaboradores afirmam que se pode constatar que no Brasil existe respaldo ético aos cuidados paliativos, que abrangem a limitação de tratamento considerado fútil ou inútil ${ }^{2}$.

\section{Fatores históricos da pessoa}

O histórico socioeconômico, a qualidade de vida prévia e as comorbidades da pessoa são alguns dos fatores que compõem o processo de agregação consensual para a tomada de decisão da $\mathrm{AM}^{3}$. Por exemplo, o etilismo, o tabagismo e o uso de drogas podem repercutir negativamente ou mesmo agravar a evolução clínica da pessoa com lesão encefálica significativa. Comorbidade é considerada como um dos principais indicadores preditivos de mortalidade e morbidade ${ }^{15}$.

\section{Fatores prognósticos}

Em 2000, a Brain Trauma Foundation (BTF) publicou um documento com o objetivo de identificar indicadores precoces de prognóstico em traumatismo cranioencefálico grave baseados na escala de resultados de Glasgow (ERG) ${ }^{16}$. Originalmente, a ERG é uma escala de cinco itens: 1) óbito; 2) estado vegetativo persistente; 3 ) incapacidade grave; 4) incapacidade moderada; 5) boa recuperação. Os indicadores endossados pela The American Association of Neurological Surgeons e World Health Organization's Committee on Neurotrauma e que possuem valor preditivo positivo (VPP) de pelo menos $70 \%$ são a pontuação inicial na escala de coma de Glasgow (ECG), a idade, o reflexo pupilar, a hipotensão, e achados específicos no exame de imagem por tomografia computadorizada (TC) ${ }^{16}$.

A ECG avalia o nível de consciência em quadros neurológicos agudos e baseia-se em três quesitos: abertura ocular, resposta motora e resposta verbal. Quanto menor a pontuação inicial, maior comprometimento do nível de consciência e uma probabilidade crescente de desfecho desfavorável na ERG. A ECG deveria ser medida de maneira padronizada por meio da interação com a pessoa por equipe treinada (por exemplo, aplicação de um estímulo doloroso em pessoas incapazes de seguir comandos). Para fins prognósticos, a mensuração deveria ser feita apenas após ressuscitação pulmonar e hemodinâmica e após sedação farmacológica ou metabolização de agentes paralisadores. Caso a pontuação inicial na ECG seja confiavelmente obtida e não influenciada por medicação pré-hospitalar ou intubação, aproximadamente $20 \%$ dos pacientes com menores pontuações iniciais sobreviverão e de $8 \%$ a $10 \%$ apresentarão ERG 4 ou $5^{16}$.

Com relação à idade, há crescente probabilidade de desfecho desfavorável com o aumento da idade. Essa variável não está sujeita à variabilidade de medida pelo observador e deveria ser obtida na admissão, preferencialmente com documentação comprobatória. A idade é considerada forte preditor independente de mortalidade e morbidade, principalmente acima dos 60 anos ${ }^{16}$.

O diâmetro pupilar e o reflexo pupiloconstritor à luz são dois importantes parâmetros associados ao prognóstico. A ausência do reflexo pupilar à luz bilateralmente é importante preditor de desfecho desfavorável. Este parâmetro deveria ser avaliado após ressuscitação pulmonar e hemodinâmica por equipe treinada. Ao exame, deve-se registrar evidência de trauma orbital direto, resposta assimétrica à luz, assimetria em repouso, pupila fixa (uma ou ambas), pupila dila- 
tada (uma ou ambas). Recomendações para mensuração desse parâmetro estão descritas pela BTF ${ }^{16}$.

Pressão sanguínea sistólica menor que 90 $\mathrm{mmHg}$ apresenta $67 \%$ de VPP para desfecho desfavorável e, quando combinada com hipóxia, um valor de $79 \%$ de VPP. As pressões sanguíneas sistólica e diastólica deveriam ser frequentemente mensuradas por equipe treinada usando o sistema mais acurado disponível, preferencialmente que mensure pressão arterial média. Um único episódio hipotensivo está geralmente associado a um aumento em dobro da mortalidade ${ }^{16}$.

A presença de anormalidades ao exame inicial de TC consistente com TCE avaliada por médico especialista nas primeiras 12 horas da lesão, de cisternas basais comprimidas ou ausentes, de hemorragia subaracnoidea traumática (HSAt) são considerados importantes fatores prognósticos para o desfecho desfavorável. As cisternas comprimidas ou a sua ausência deveriam ser mensuradas na linha cerebral média; HSAt deve ser observada nas cisternas basais ou sobre a convexidade; o desvio da linha média deve ser mensurado no nível do septo pelúcido. Achados de TC podem gerar informação prognóstica significante principalmente por serem analisadas rotineiramente em pacientes com TCE grave ${ }^{16}$.

Ainda que toda análise de fatores prognósticos de vida e de incapacidade deva ser feita com ponderações cautelosas, os parâmetros clínicos acima descritos com significância prognóstica em pacientes com TCE grave poderiam ser considerados no processo de agregação de fatores para a AM. Analisados em conjunto, esses parâmetros podem trazer informação que impacte na qualidade de vida futura de pessoas com TCE, auxiliando as discussões acerca da AM.

\section{Fatores de declínio clínico e/ou funcional}

Em 2011, o Royal College of General Practioners (RCGP) publicou um guia de indicador prognóstico padrão-ouro para dar suporte aos médicos quanto ao reconhecimento precoce de pacientes no fim da vida - o The gold standard framework prognostic indicator guidance (GSF) ${ }^{15}$. Cuidado de fim de vida foi definido como o destinado a pessoas que estão se aproximando do fim da vida, provavelmente nos próximos 12 meses, incluindo aquelas em morte iminente (horas ou dias) ${ }^{15}$. O guia proposto pelo RCGP é baseado em três "disparadores" para a terminalidade e que suscitam a necessidade de reflexões sobre AM.

Dois desses "disparadores" são indicadores gerais de declínio clínico e/ou funcional (deteriora- ção, aumento crescente de dependência ou escolha para a não realização de cuidado ativo) e indicadores clínicos específicos relacionados a certas condições de saúde, como câncer, doença pulmonar obstrutiva crônica, insuficiência cardíaca congestiva, doença renal, doença de Alzheimer, doença de Parkinson, doença do neurônio motor, esclerose múltipla, fragilidade, acidente vascular encefálico (AVE) e coma, e esclerose lateral amiotrófica ${ }^{15}$. Interessantemente, a literatura apresenta critérios de elegibilidade para a abordagem hospice ou para cuidados paliativos, que estão em concordância com os critérios gerais e específicos propostos pelo RCGP ${ }^{17,18}$.

Os critérios gerais de declínio clínico e funcional descritos são infeç̧ões recorrentes ou intratáveis (pneumonia, sepse ou infecção do trato urinário superior); perda de peso progressiva não intencional e não associada à depressão ou diuréticos (maior que $10 \%$ nos últimos seis meses; maior que $7,5 \%$ nos últimos três meses); albumina sérica menor que 2,5 dg/l; disfagia, levando à aspiração recorrente e/ou ingestão oral inadequada; hospitalizações frequentes; declínio do status de desempenho funcional (limitação de autocuidado e restrição ao leito) e aumento da dependência na maioria das atividades de vida diária; comorbidades; declínio físico geral e aumento da necessidade de suporte; doença avançada; diminuição da resposta aos tratamentos, diminuindo reversibilidade; escolha por não receber mais tratamento ativo; evento sentinela (queda grave, luto) ${ }^{15,17,18}$. O declínio deve ser estabelecido e documentado a partir de informações objetivas dos registros de cada pessoa.

Os critérios específicos descritos para condições neurológicas de saúde são anormalidade de resposta de tronco cerebral; ausência de resposta verbal; ausência de resposta de retirada à dor; escala de performance paliativa igual ou menor a $40 \%$, ou seja, maximamente, o paciente permanece a maior parte do tempo acamado, é incapaz para a maioria das atividades, depende de uma assistência quase completa, apresenta ingesta geralmente reduzida e nível de consciência caracterizado por sonolência e/ou confusão; creatinina sérica maior que $1,5 \mathrm{mg} / \mathrm{dl}$; pneumonia de aspiração; infecção do trato urinário superior (pielonefrite); úlceras de decúbito refratárias de estágio 3 ou 4; febre recorrente após antibioticoterapia; deterioração progressiva na função física e/ou cognitiva mesmo com terapia otimizada; disfagia; sepses; dispneia, insuficiência respiratória; história atual de aspiração pulmonar, sem resposta efetiva às intervenções fonoaudioló- 
gicas ${ }^{15,17,18}$. Esses critérios específicos deveriam ser usados em conjunto com os gerais e analisados em função do tempo e com os outros fatores do processo de agregação.

\section{A pergunta surpresa}

No The gold standard framework prognostic indicator guidance, publicado pelo RCGP, consta a pergunta surpresa: você se surpreenderia se esta pessoa morresse nos próximos meses, semanas ou dias? ${ }^{15}$ A resposta positiva a esta pergunta, ainda que subjetiva, é considerada também um disparador para o aprofundamento das discussões sobre AM, além dos critérios gerais e específicos apresentados.

\section{Reflexões}

Considerando os aspectos éticos e normativos pertinentes à $\mathrm{AM}$ e aos cuidados paliativos, o histórico da pessoa, os indicadores prognósticos póslesão neurológica e os critérios de declínio clínico e/ ou funcional como fatores de agregação centrados na pessoa, as reflexões que perpassam tal processo são referentes ao diagnóstico, à proposição de medidas diagnósticas e terapêuticas, ao prognóstico e à espiritualidade. Há precisão no diagnóstico médico clínico e neurológico? A medida que está sendo proposta, seja diagnóstica, seja terapêutica, é capaz de proporcionar maior prognóstico de vida com melhor qualidade de vida futura? Esta medida é capaz de proporcionar conforto à pessoa? E a espiritualidade da pessoa e da família? Há considerações que interferem na tomada de decisão? Centrado na pessoa, o processo para tomada de decisão na AM deve ser prévia e concomitantemente acompanhado pela abordagem paliativa baseada em medidas de conforto, que se tornará, por fim, exclusiva.

\section{Considerações finais}

O objetivo do presente artigo foi discorrer a respeito da AM como processo abrangente de agregação consensual de fatores centrado na pessoa. Não se pretende esgotar sistematicamente o tema da AM na pessoa com lesão encefálica, particularmente a vítima de grandes traumas e agravos que necessitam cuidados prolongados à saúde e de reinserção social. Os autores buscaram aprofundar a discussão sobre a limitação de esforço terapêutico com a perspectiva de uma tomada de decisão complexa, multifacetada e acompanhada pela intensificação dos cuidados paliativos, buscando evitar decisões unilaterais, lineares e simplistas.

Os autores esperam com a proposta ética e técnica descrita neste artigo que outras perspectivas possam ser ampliadas: da limitação de esforço terapêutico para esforço máximo de cuidado; de critérios obscuros de LET para elegibilidade discutida, consensual e compartilhada da AM centrada na pessoa; da participação da pessoa, da família e da equipe multiprofissional na $A M$; da linearidade do modelo curativo-paliativo para a sincronia dos modelos curativo/paliativo; da equipe multidisciplinar para a equipe transdisciplinar de "olhar" humanizado para a pessoa com lesão encefálica grave, em terminalidade ou não. Esperam ainda que a proposta apresentada possa estimular o aprofundamento das discussões da AM em instituições que prestam assistência a essas pessoas e famílias, revelando o respeito incondicional à pessoa.

\section{Referências}

1. Siqueira JE. Definindo e aceitando a terminalidade da vida. In: Moritz RD, organizadora. Conflitos bioéticos do viver e do morrer. Brasília: CFM; 2011. p. 15-24.

2. Moritz RD, Rossini JP, Deicas A. Cuidados paliativos na UTI: definições e aspectos ético-legais. In: Moritz RD. Cuidados paliativos nas unidades de terapia intensiva. São Paulo: Atheneu; 2012. p. 19-32.

3. Herreros B, Palacios G, Pacho E. Limitación del esfuerzo terapéutico. Rev Clin Esp. 2012;212(3):13440.

4. Biondo CA, Silva MJP, Secco LMD. Distanásia, eutanásia e ortotanásia: percepções dos enfermeiros de unidades de terapia intensiva e implicações na assistência. Rev Latinoam Enferm. 2009;17(5):613-9.

5. Lanken PN, Terry PB, Delisser HM, Fahy BF, Hansen-Flaschen J, Heffner JE et al. An official american thoracic society clinical policy statement: palliative care for patients with respiratory diseases and critical illnesses. Am J Respir Crit Care Med. 2008;177(8):912-27.

6. Moritz RD, Deicas A, Capalbo M, Forte DN, Kretzer LP, Lago P et al. II Fórum do "Grupo de Estudos do Fim da Vida do Cone Sul": definições, recomendações e ações integradas para cuidados paliativos na unidade de terapia intensiva de adultos e pediátrica. Rev Bras Ter Intensiva. 2011;23(1):24-9. 
7. Sociedad Española de Medicina Intensiva, crítica y unidades coronarias. Indicadores de calidad en el enfermo crítico. [Internet]. 2011 (acesso 31 jul. 2013). Disponível: http://www.semicyuc.org/ sites/default/files/actualizacion_indicadores_calidad_2011.pdf

8. National Health and Medical Research Council. Ethical guidelines for the care of people in postcoma unresponsiveness (vegetative state) or a minimally responsive state. [Internet]. Austrália: NHMRC; 2008 (acesso 31 jul. 2013). Disponível: http://www.nhmrc.gov.au/_files_nhmrc/ publications/attachments/e81.pdf

9. Ortega S, Cabré L. Limitación del esfuerzo terapêutico. [Internet]. Libro Electrónico de Medicina Intensiva. 2008 (acesso 31 jul. 2013). Disponível: intensivos/uninet.edu/03/0303.html

10. Koerich MS, Machado RR, Costa E. Ética e bioética: para dar início à reflexão. Texto \& Contexto Enferm. 2005;14(1):106-10.

11. Torre JHR. Ortotanásia não é homicídio nem eutanásia. In: Moritz RD, organizadora. Conflitos bioéticos do viver e do morrer. Brasília: CFM; 2011. p. 157-84.

12. Conselho Federal de Medicina. Resolução ${ }^{\circ}{ }^{\circ} 1.805$, de 28 de novembro de 2006 . Na fase terminal de enfermidades graves e incuráveis é permitido ao médico limitar ou suspender procedimentos e tratamentos que prolonguem a vida do doente, garantindo-lhe os cuidados necessários para aliviar os sintomas que levam ao sofrimento, na perspectiva de uma assistência integral, respeitada a vontade do paciente ou de seu representante legal. [Internet]. (acesso 31 jul. 2013). Disponível: http://www.portalmedico.org.br/resolucoes/cfm/2006/1805_2006.htm

13. Conselho Federal de Medicina. Resolução $n^{\circ} 1.931$, de 24 de setembro de 2009. Código de Ética Médica. [Internet]. (acesso 31 jul. 2013). Disponível: http://www.portalmedico.org.br/ resolucoes/CFM/2009/1931_2009.pdf

14. Conselho Federal de Medicina. Resolução $\mathrm{n}^{\circ}$ 1.995, de 9 de agosto de 2012. Dispõe sobre as diretivas antecipadas de vontade dos pacientes. [Internet]. (acesso 31 jul. 2013]. Disponível: http://www.portalmedico.org.br/resolucoes/CFM/2012/1995_2012.pdf

15. Royal College of General Practioners. The GSF prognostic indicator guidance: the National GSF Center's guidance for clinicians to support earlier recognition of patients nearing the end of life. [Internet]. 2011 (acesso 31 jul. 2013). Disponível: http://www.goldstandardsframework. org.uk/cd-content/uploads/files/General\%20Files/Prognostic\%20Indicator\%20Guidance\%20 October\%202011.pdf

16. Chesnut RM, Ghajar J, Maas AIR, Marion DW, Servadei F, Teasdale GM et al. Early indicators of prognosis in severe traumatic brain injury. [Internet]. 2000 (acesso 31 jul. 2013). Disponível: http://www.braintrauma.org/pdf/protected/prognosis_guidelines.pdf

17. Stuart B. The NHO medical guidelines for non-cancer disease and local medical review policy: hospice access for patients with diseases other than cancer. Hosp J. 1999;14(3-4):139-54.

18. Arantes ACLQ. Indicações de cuidados paliativos. Manual de cuidados paliativos/Academia Nacional de Cuidados Paliativos. Rio de Janeiro: Diagraphic; 2009. p. 20-36.

\section{Participação dos autores}

Revisão da literatura e redação, discussão e revisão do manuscrito: Henrique de Alencar Gomes. Todos os demais autores participaram da discussão e revisão crítica do manuscrito.

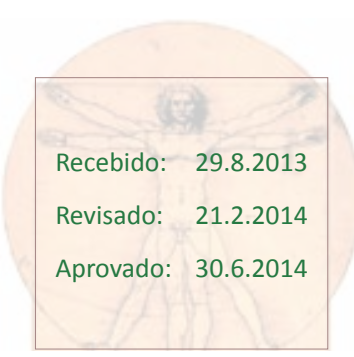

